\title{
Uma Análise dos Cursos de Licenciatura sobre a Formação Docente para Utilização das TIC na Educação
}

\author{
Francisca Lindvania da Silva Vieira ${ }^{1}$ e Emmanuel Sávio Silva Freire ${ }^{2}$ \\ ${ }^{1}$ Secretaria de Apoio as Tecnologias Educacionais - Universidade Estadual do Ceará (UECE) \\ Rua José Hamilton de Oliveira, 160 - 62.930-000 - Limoeiro do Norte - CE - Brasil \\ ${ }^{2}$ Departamento de Ensino - Instituto Federal do Ceará (IFCE/Campus Morada Nova) \\ Morada Nova, Brasil \\ francisca.lindvaniadaluno.uece.br, savio.freiredifce.edu.br
}

\begin{abstract}
Information and Communication Technologies (ICT) are increasingly present in people's lives, including in the educational environment. From the conception that these resources can be used as pedagogical support for teachers and students, the need arises to investigate whether teachers are being prepared to use these resources in the classroom. Therefore, the present article carried out a bibliographical and documentary study with the Pedagogical Projects of the Courses (PPC) of some degree courses, in Portuguese Literature, History, Biological Sciences, Physics, Chemistry and Mathematics offered in the State of Ceará. As a main result, it was verified that improvements should be made in these courses to enable teacher training to effectively train their students to use ICT as a pedagogical resource.
\end{abstract}

Resumo. As Tecnologias da Informação e Comunicação (TIC) estão cada vez mais presentes na vida das pessoas, inclusive no ambiente educacional. A partir da concepção de que estes recursos podem ser usados como apoio pedagógico para os professores e alunos, surge a necessidade de investigar se os professores estão sendo preparados para utilização destes recursos em sala de aula. Para tanto, o presente artigo realizou um estudo bibliográfico e documental com os Projetos Pedagógico dos Cursos (PPC) de alguns cursos de Licenciatura, em Letras-Português, História, Ciências Biológicas, Física, Química e Matemática ofertados no Estado do Ceará. Como principal resultado, foi constatado que melhorias devem ser realizadas nesses cursos para possibilitar que a formação docente capacite efetivamente seus discentes para usar as TIC como recurso pedagógico.

\section{Introdução}

O papel docente está sendo transformado devido à gama de Tecnologias da Informação e Comunicação (TIC) que adentraram ao meio educacional, requerendo mudanças no processo de ensino e aprendizagem (SILVEIRA, 2015). Consequentemente, as TIC despertaram mudanças nas necessidades e nos interesses dos alunos, requisitando uma mudança de comportamento e uma reconstrução das metodologias utilizadas pelos professores. Assim, é cabível repensar e modificar o contexto educacional, pois os sujeitos aprendentes possuem cada vez mais capacidade de interação, dispondo de um conhecimento de bastante significância (VIEIRA, 2018). 
VII Congresso Brasileiro de Informática na Educação (CBIE 2018)

Anais do XXIV Workshop de Informática na Escola (WIE 2018)

Diante das mudanças causadas na sociedade, e consequentemente na educação pelas novas formas de comunicação intermediadas pelas TIC, surge a necessidade de aprimorar as metodologias, e se necessário aprender a ensinar, e aprender a aprender, com foco nos recursos que as TIC oferecem (VIEIRA, 2018). Logo, para que os modelos de ensino e aprendizagem vigentes se adequem aos anseios e perspectivas da era digital, é fundamental que os professores estejam conscientes e preparados para aceitar, conhecer e se adaptar a esse novo contexto. Para tanto, entender o processo de formação docente é um passo importante para compreender sua postura em relação as TIC, o modo como eles lidam com estes recursos e os utilizam no processo de ensino e aprendizagem.

Segundo a Resolução $n^{\circ}$ 01/2002, os cursos de Licenciatura têm como objetivo a formação da atividade docente, considerando "(i) o ensino visando à aprendizagem do aluno, (ii) o acolhimento e o trato da diversidade, (iii) o exercício de atividades de enriquecimento cultural, (iv) o aprimoramento em práticas investigativas, (v) a elaboração e a execução de projetos de desenvolvimento dos conteúdos curriculares, (vi) o uso de tecnologias da informação e da comunicação e de metodologias, estratégias e materiais de apoio inovadores, e (vii) o desenvolvimento de hábitos de colaboração e de trabalho em equipe" (RESOLUÇÃO 01/2002, p. 1). Assim, essa resolução indica que as TIC devem estar presentes na formação dos professores. Seguindo essa resolução, a Universidade Estadual do Ceará (UECE) oferece nove cursos de Licenciatura na Faculdade de Filosofia Dom Aureliano Matos (FAFIDAM). Assim, surge a seguinte indagação: "A formação docente oferecida nos cursos de Licenciatura da FAFIDAM proporciona a discussão das TIC no processo de ensino e aprendizagem?".

Esse artigo teve como objetivo desvelar a proposta da formação docente dos cursos de licenciatura oferecidos pela FAFIDAM em relação as TIC. Mais especificamente, esta pesquisa teve os seguintes objetivos específicos: (i) Analisar os Projetos Pedagógicos do Curso (PPC) dos cursos de Licenciatura em Letras-Português, História, Ciências Biológicas, Física, Química e Matemática oferecidos pela FAFIDAM, (ii) Demonstrar como esses cursos de Licenciatura abordam a formação para o uso das TIC, e (iii) Reafirmar a importância das TIC na formação do profissional docente. Vale ressaltar que esse estudo possibilitará o entendimento de como os professores estão sendo formados para utilização das TIC, e, diante dos resultados, refletir sobre o contexto e de como esse processo de formação pode estar influenciando de forma negativa ou positiva, para concretização da proposta do uso das TIC em sala de aula.

A pesquisa realizada foi documental, que teve como instrumento principal os PPC dos cursos de Licenciatura da FAFIDAM. O estudo buscou conhecer a estrutura dos cursos e se as TIC estavam inseridas na proposta de formação dos professores. Os dados obtidos com a análise dos PPC foram complementados com pesquisas existentes na literatura e que norteiam os estudos em relação à utilização das novas tecnologias em sala de aula e à importância da formação adequada dos professores. Adicionalmente, este artigo está organizado como segue. A seção 2 apresenta os conceitos relacionados com a formação de professores e as competências curriculares relacionadas aos cursos de licenciatura. A metodologia utilizada é apresentada na seção 3. A seção 4 detalha os resultados e as discussões relacionados à análise dos PPC dos cursos de licenciatura. Finalmente, as considerações finais são apresentadas na seção 5. 
VII Congresso Brasileiro de Informática na Educação (CBIE 2018)

Anais do XXIV Workshop de Informática na Escola (WIE 2018)

\section{Formação de Professores}

O professor tem um papel importante no processo de ensino e aprendizagem, sendo este o responsável por mediar o conhecimento e proporcionar aos alunos oportunidades para construção do saber. Para que desenvolva habilidades, e se torne capaz de lecionar é necessário passar por um processo de formação.

Neste sentido, Saviani (2009) afirma que, em 1684, foi instituído o primeiro estabelecimento destinado a formação de professores, e, após a revolução francesa, começaram a pensar sobre a instrução dos povos. Assim, foram criadas as primeiras Escolas Normais, que eram encarregadas de formar professores de nível primário e superior. Ao longo do século XIX, as Escolas Normais foram instaladas em países como França, Itália, Alemanha, Inglaterra, e Estados Unidos. No Brasil, a formação de professores passou a ser considerada no período após a independência, com a cogitação da organização da instrução popular, iniciando pela instrução dos professores pelo ensino mútuo, passando pelas escolas normais, organização e implantação dos cursos de pedagogia e licenciatura oferecidos pelos Institutos Superiores de Educação e Escolas Normais Superiores.

A Lei $n^{\circ}$ 9394-96 (BRASIL, 2017) relata que a formação de docentes para atuar na educação básica far-se-á em nível superior, em curso de licenciatura plena, admitida, como formação mínima para o exercício do magistério na educação infantil e nos cinco primeiros anos do ensino fundamental, a oferecida em nível médio, na modalidade normal. Assim, essa formação deve se basear nos seguintes fundamentos: "I - a presença de sólida formação básica, que propicie o conhecimento dos fundamentos científicos e sociais de suas competências de trabalho; II - a associação entre teorias e práticas, mediante estágios supervisionados e capacitação em serviço; III - o aproveitamento da formação e experiências anteriores, em instituições de ensino e em outras atividades" (BRASIL, 2017, p. 42).

Vale ressaltar que o processo de formação dos professores vem se modificando ao longo dos anos. Percebe-se que durante essa transição foram instituídos diferentes pontos e exigências para se obter o título necessário para lecionar. Leite (2007) corrobora com essa mudança ressaltando a necessidade de assegurar aos professores uma formação que possibilite lidar com as várias dimensões do processo formativo dos alunos, englobando a cognição a afetividade, a educação de sentidos, a estética, ética e os valores emocionais. Além desses aspectos, diante da sociedade digital, é necessário que os professores desenvolvam a capacidade de lidar com as ferramentas tecnológicas, e inseri-las em sala de aula. Para isso, é necessário que os professores estejam contemplando em sua formação a abordagem das TIC.

Segundo Stahl (1997, p. 6), "Os professores precisam entender que a entrada da sociedade na era da informação exige habilidades que não têm sido desenvolvidas na escola, e que a capacidade das novas tecnologias de propiciar aquisição de conhecimento individual e independente, implica num currículo mais flexível, desafia o currículo tradicional e a filosofia educacional predominante, e depende deles as oportunidades de emprego e realização pessoal e profissional". Consequentemente, o professor precisa estar consciente do seu papel, e preparado para inserir os novos recursos da tecnologia computacional em sua metodologia. Entretanto, muitos docentes encontram dificuldades na utilização das TIC (SCHUHMACHER, ALVES FILHO e SCHUHMACHER, 2017). 
VII Congresso Brasileiro de Informática na Educação (CBIE 2018)

Anais do XXIV Workshop de Informática na Escola (WIE 2018)

Além disso, Paiva (2013) afirma que os projetos de formação de professores oferecidos pelas universidades ainda não abordam o uso da tecnologia. Existindo apenas alguns professores que de forma isolada e independente adotam a tecnologia em suas aulas. Assim, os professores acabam não usufruindo dos benefícios da utilização das TIC em favor do processo de ensino e aprendizagem.

\section{Competências Curriculares dos Cursos de Licenciatura}

O currículo não deve ser visto apenas como um encadeamento de disciplinas, pois é composto pelos "conteúdos a ser ensinados e aprendidos, pelas experiências de aprendizagem escolares a serem vividas pelos alunos, pelos planos pedagógicos elaborados por professores, escolas e sistemas educacionais, pelos objetivos a serem alcançados por meio do processo de ensino e pelos processos de avaliação que terminam por influir nos conteúdos e nos procedimentos selecionados nos diferentes graus da escolarização" (MOREIRA e CANDAU, 2007, p.18). Além disso, Silva (2010) indica que outro componente do currículo está relacionado com os aspectos que ocorrem no ambiente escolar que não estão descritos no currículo oficial. Logo, a relação entre professores e alunos, a troca de experiência entre os mesmos e a forma que os professores abordam um determinado conteúdo forma o currículo oculto.

Assim, a organização curricular deve proporcionar que o aluno tenha acesso aos conteúdos a ser estudados proporcionando que os mesmos possam integrar os conhecimentos adquiridos com a prática profissional. Neste sentido, a formação de professores deve considerar esses elementos do currículo para desenvolver as seguintes competências nos futuros docentes: “(Ci) o ensino visando à aprendizagem do aluno, (Cii) o acolhimento e o trato da diversidade, (Ciii) o exercício de atividades de enriquecimento cultural, (Civ) o aprimoramento em práticas investigativas, (Cv) a elaboração e a execução de projetos de desenvolvimento dos conteúdos curriculares, (Cvi) o uso de tecnologias da informação e da comunicação e de metodologias, estratégias e materiais de apoio inovadores, e (Cvii) o desenvolvimento de hábitos de colaboração e de trabalho em equipe" (RESOLUÇÃO 01/2002, p. 1).

Vale ressaltar que a formação dos professores, segundo a Resolução 01/2002, deve considerar a inclusão das TIC no processo de ensino e aprendizagem. Logo, os cursos de licenciatura precisam ter em seu currículo formas de desenvolver a competência Civ que estejam especificadas no projeto pedagógico do curso (PPC). Além disso, o PPC de um curso de licenciatura deve considerar que: "a formação esperada deva garantir a constituição das competências objetivadas na Educação Básica; o desenvolvimento das competências exija que a formação contemple diferentes âmbitos do conhecimento profissional do professor; a seleção dos conteúdos das áreas de ensino da Educação Básica oriente-se para além do que os professores irão ensinar nas diferentes etapas da escolaridade; os conteúdos a serem ensinados na escolaridade básica devam ser tratados de modo articulado com suas didáticas específicas; a avaliação tenha, como finalidade: a orientação do trabalho dos formadores, a autonomia dos futuros professores em relação ao seu processo de aprendizagem e a qualificação dos profissionais aptos a iniciarem a carreira" (JUNQUEIRA e MANRIQUE, 2015, p.628).

Por consequência, a utilização das TIC no processo de formação docente deve possibilitar que os futuros professores possam incluir as TIC no processo de ensino e 
VII Congresso Brasileiro de Informática na Educação (CBIE 2018)

Anais do XXIV Workshop de Informática na Escola (WIE 2018)

aprendizagem, possibilitando que os seus alunos experimentem novas formas de aprender. Entretanto, essa habilidade deve ser desenvolvida durante o curso de licenciatura por meio de disciplinas, atividades complementares, práticas como componentes curriculares (PCC) ou estágios supervisionados que devem estar previstas no PPC desses cursos. Além disso, o currículo oculto pode possibilitar que os discentes dos cursos de formação de professores vivenciem e desenvolvam essa habilidade, porém essas práticas deveriam estar contidas e descritas no currículo oficial, pois não se pode garantir que sempre essa discussão acerca da inclusão das TIC seja realizada.

\section{Metodologia}

Este trabalho define-se como um estudo documental e bibliográfico, realizado por meio de documentos didáticos e documentos publicados. O objetivo da pesquisa foi desvelar a proposta da formação docente dos cursos de licenciatura oferecidos pela FAFIDAM/UECE em relação as TIC. Para coleta das informações, utilizou-se a pesquisa bibliográfica e a análise dos projetos pedagógicos dos cursos de Licenciatura em Letras-Português, História, Ciências Biológicas, Física, Química e Matemática da referida faculdade.

Esta pesquisa está classificada de acordo com as definições de Joye (2014): (i) Aplicada, pois a natureza da mesma objetiva gerar conhecimentos para a solução de problemas específicos, (ii) Qualitativa, pois sua abordagem não requer uso de métodos estatísticos, (iii) Exploratória, pois seus objetivos proporcionam uma maior familiaridade com o tema, tornando-o explícito e construindo hipóteses, (iv) Bibliográfica, pois seus procedimentos técnicos consideraram materiais já produzidos (livros, artigos e periódicos), (v) Documental, pois foi elaborada a partir de documentos que ainda não receberam tratamento analítico, e (vi) Estudo de documentos oficiais, devido a coleta de informações ter sido realizadas em leis e programas de ensino. Em relação aos passos metodológicos, foi analisada a Resolução $n^{\circ}$ 01/2002 com o intuito de identificar quais eram as competências necessárias que os egressos precisavam desenvolver em relação à utilização das TIC no processo de ensino e aprendizagem. Em seguida, foi realizada a busca dessas competências nos PPC dos cursos de licenciatura da FAFIDAM. Além disso, foram consideradas as disciplinas e os seus respectivos Programas de Unidade Didática (PUD). Finalmente, foram identificados os pontos convergentes e divergentes entre a resolução e os PPC.

Para mensurar os resultados, adaptou-se a escala proposta por Freire (2017). Assim, a escala utilizada foi composta pelas seguintes opções: (i) Contempla totalmente: indica que a competência requerida pela resolução possui um ou mais equivalentes tanto nas competências listadas no PPC quanto nas disciplinas da matriz curricular; (ii) Contempla: estabelece que por mais que exista uma ou mais competências no PPC e uma ou mais disciplinas da matriz curricular, a equivalência com a competência da resolução não é completa; (iii) Contempla parcialmente: aponta que a competência da resolução possui um ou mais equivalentes nas competências do PPC ou nas disciplinas da matriz curricular; (iv) Não contempla: determina que uma competência da resolução não possui um equivalente nem nas competências do PPC nem nas disciplinas da matriz curricular.

\section{Resultados e Discussões}

Esta seção aborda sobre os PPC dos cursos de licenciatura em Letras-Português, História, Ciências Biológicas, Física, Química e Matemática ofertados pela instituição onde foi 
VII Congresso Brasileiro de Informática na Educação (CBIE 2018)

Anais do XXIV Workshop de Informática na Escola (WIE 2018)

realizada a pesquisa, para contextualizar e apresentar as competências consideradas na formação docente nessas áreas. Além disso, é detalhada a comparação entre essas competências com as dispostas nas Resolução $n^{\circ}$ 01/2002. Finalmente, as discussões sobre a comparação são apresentadas.

\subsection{PPC dos Cursos de Licenciatura da FAFIDAM}

A FAFIDAM foi inaugura em 1968 e tem desempenhado um importante papel na formação de professores nas regiões do Médio e Baixo Jaguaribe. Assim, tem ofertados oito cursos de licenciatura regulares (Ciências Biológicas, Física, Geografia, História, Letras Inglês, Letras Português, Matemática, Pedagogia e Química) e o curso de licenciatura em Educação no Campo. Além disso, a maioria dos profissionais formados tem desempenhado funções na área educacional (UECE, 2018).

Em relação à formação docente oferecida nos cursos de licenciatura em LetrasPortuguês [LP], História [H], Ciências Biológicas $[\mathbf{C B}]$, Física $[\mathbf{F}]$, Química $[\mathbf{Q}]$ e Matemática $[\mathbf{M}]$, pode-se notar que todos os cursos supracitados pretendem desenvolver a competência dos seus discentes em relação à utilização das TIC no processo de ensino e aprendizagem. O detalhamento dessas competências é apresentado no Quadro 1. Além disso, o curso de licenciatura em Matemática apresenta o maior número de competências relacionadas com a utilização das TIC no processo de ensino e aprendizagem dos seus discentes. Em contrapartida, o curso de Ciências Biológicas possibilita o desenvolvimento de apenas a relação entre a ciência, a tecnologia e a sociedade.

Quadro 1. Competências dos cursos de licenciatura relacionadas com as TIC.

\begin{tabular}{|c|l|}
\hline CURSO & \multicolumn{1}{c|}{ COMPETÊNCIA ${ }^{\mathbf{1}}$ (PCC) } \\
\hline$[\mathbf{L P}]$ & $\begin{array}{l}\text { [CLP1] Atitude investigativa que favoreça construção contínua do conhecimento na área e sua } \\
\text { aplicação na área de novas tecnologias. }\end{array}$ \\
\hline$[\mathbf{H}]$ & $\begin{array}{l}\text { [CH1] Uso de tecnologias da informação e da comunicação e de metodologias, estratégias e materiais } \\
\text { de apoio inovadores. }\end{array}$ \\
\hline$[\mathbf{C B}]$ & {$[\mathbf{C C B 1 ] ~ E s t a b e l e c e r ~ r e l a c ̧ o ̃ e s ~ e n t r e ~ c i e ̂ n c i a , ~ t e c n o l o g i a ~ e ~ s o c i e d a d e . ~}$} \\
\hline [F] & $\begin{array}{l}\text { [CF1] O uso de novas tecnologias e o desenvolvimento da capacidade crítica e criativa. Utilizar diferentes } \\
\text { tenologias educativas como aporte para o processo de ensino-aprendizagem; [CF2] Avaliar as } \\
\text { implicações éticas, ambientais, sociais e epistemológicas do conhecimento científico, das tecnologias e } \\
\text { dos serviços e produtos gerados pela sociedade; [CF3] Utilizar os diversos recursos da informática, } \\
\text { dispondo de noções de linguagem computacional. }\end{array}$ \\
\hline [Q] & $\begin{array}{l}\text { [CQ1] Saber fazer busca e identificar fontes de informação relevantes para a Química, inclusive as } \\
\text { disponíveis na WEB e outras modalidades eletrônicas, que possibilitem a contínua atualização técnica, } \\
\text { científica, humanística e pedagógica; [CQ2] Possuir conhecimentos básicos do uso de computadores e } \\
\text { sua aplicação em ensino de Química. }\end{array}$ \\
\hline [M] & $\begin{array}{l}\text { [CM1] O uso de diversos recursos tecnológicos da informática e da comunicação.; [CM2] Ter domínio } \\
\text { sobre os diversos recursos pedagógicos, incluindo as novas tecnologias da informação e comunicação e } \\
\text { avaliando seus potenciais para o processo ensino - aprendizagem; [CM3] Capacidade de aprendizagem } \\
\text { continuada e de aquisição e utilização de novas ideias e tecnologias; [CM4] Capacidade de lidar com } \\
\text { novas tecnologias no ensino da matemática; [CM5] Dotar o profissional docente de uma base } \\
\text { fundamental para fazer uso apropriado de novas tecnologias, como também compreender e utilizar } \\
\text { definições, teoremas, exemplos, propriedades, conceitos e técnicas matemáticas. }\end{array}$ \\
\hline
\end{tabular}

O Quadro 2 apresenta as disciplinas presentes no PPC dos cursos que estão relacionadas com a competência de inclusão das TIC no processo de ensino e aprendizagem. É possível perceber que apenas os cursos Letras-Português, Física, Química e Matemática

\footnotetext{
1 Para identificar cada competência do PPC individualmente e por curso, foi definida a seguinte sigla: C (competência) + iniciais do curso + número. Essas siglas serão utilizadas desse ponto em diante.
} 
VII Congresso Brasileiro de Informática na Educação (CBIE 2018)

Anais do XXIV Workshop de Informática na Escola (WIE 2018)

apresentam disciplinas para essa finalidade. Além disso, o curso de História, por mais que tenha uma competência associada, não apresenta nenhuma disciplina. $\mathrm{O}$ curso de Ciência Biológicas possui disciplinas para a inclusão das TIC, porém são optativas.

Quadro 2. Disciplinas relacionadas com as TIC.

\begin{tabular}{|c|c|c|c|}
\hline CURSO & DISCIPLINA & COMPETÊNCIA & EMENTA DA DISCIPLINA \\
\hline \multirow[b]{2}{*}[\mathrm{LP}]{} & $\begin{array}{lr}\text { [D1] } & \text { Oficina IV } \\
\text { em } & \text { Língua } \\
\text { Portuguesa }(\mathbf{O B R})\end{array}$ & $\begin{array}{l}\text { O Uso de Novas Tecnologias } \\
\text { para o Ensino de Língua } \\
\text { Portuguesa e Literatura. }\end{array}$ & Não apresenta. \\
\hline & $\begin{array}{l}\text { [D2] Tópico em } \\
\text { letramento e } \\
\text { novas tecnologias } \\
\text { (OBR) }\end{array}$ & $\begin{array}{l}\text { Implicações do uso do } \\
\text { computador e/ou efeitos da } \\
\text { multimídia no ensino- } \\
\text { aprendizagem de línguas ou } \\
\text { em outros contextos de uso } \\
\text { da escrita. }\end{array}$ & $\begin{array}{l}\text { Concepções de letramento. Letramento } \\
\text { alfabetização. Letramento e o uso de novas } \\
\text { tecnologias. Caracterização de novas práticas e } \\
\text { gêneros textuais. Implicações do uso do computador } \\
\text { e/ou efeitos da multimídia no ensino-aprendizagem } \\
\text { de línguas ou em outros contextos de uso da escrita. }\end{array}$ \\
\hline$[\mathrm{H}]$ & Não apresenta. & Não apresenta. & Não apresenta. \\
\hline \multirow[b]{2}{*}[\mathrm{CB}]{} & $\begin{array}{l}\text { [D3] Tecnologia e } \\
\text { sociedade (OPT) }\end{array}$ & $\begin{array}{l}\text { Estudo e reflexões sobre } \\
\text { Ciência, Tecnologia e } \\
\text { Sociedade: conceitos e } \\
\text { tendências. Perspectivas } \\
\text { históricas sobre ciência, } \\
\text { técnica e tecnologia. }\end{array}$ & $\begin{array}{l}\text { Estudo e reflexões sobre Ciência, Tecnologia e } \\
\text { Sociedade: conceitos e tendências. Perspectivas } \\
\text { históricas sobre ciência, técnica e tecnologia. } \\
\text { Ciência, tecnologia e sociedade no mundo atual: } \\
\text { energia, saúde e demografia, alimentação, } \\
\text { produção industrial, telecomunicações } \\
\text { transportes, produção científica nas universidades e } \\
\text { questões éticas. }\end{array}$ \\
\hline & $\begin{array}{l}\text { [D4] Informática } \\
\text { aplicada à } \\
\text { Biologia (OPT) }\end{array}$ & $\begin{array}{l}\text { Uso do computador como } \\
\text { uma ferramenta para o } \\
\text { estudo da biologia, } \\
\text { conhecimento de software } \\
\text { de biologia e o emprego da } \\
\text { internet para pesquisas } \\
\text { sobre temas específicos da } \\
\text { biologia. }\end{array}$ & $\begin{array}{l}\text { Introdução à Ciência da computação. Uso do } \\
\text { computador como uma ferramenta para o estudo da } \\
\text { biologia, conhecimento de software de biologia e o } \\
\text { emprego da internet para pesquisas sobre temas } \\
\text { específicos da biologia. A operação do computador } \\
\text { em ambiente MS-DOS e MS-WINDOWS; Estudo } \\
\text { dos conceitos elementares de informática; } \\
\text { Aplicativos básicos e sua utilização no ensino. } \\
\text { Programar aulas de biologia a distância. }\end{array}$ \\
\hline$[\mathrm{F}]$ & $\begin{array}{l}\text { [D5] Informática } \\
\text { aplicada (OBR) }\end{array}$ & Não tem descrição. & Não tem descrição. \\
\hline \multirow[t]{2}{*}{ [Q] } & $\begin{array}{l}\text { [D6] Informática } \\
\text { aplicada a } \\
\text { Química (OBR) }\end{array}$ & $\begin{array}{l}\text { Computador como uma } \\
\text { ferramenta para o estudo de } \\
\text { química; conhecimento de } \\
\text { software de química e o } \\
\text { emprego da internet para } \\
\text { pesquisas sobre temas } \\
\text { específicos da química. }\end{array}$ & $\begin{array}{l}\text { Computador como uma ferramenta para o estudo } \\
\text { de química; conhecimento de software de } \\
\text { química e o emprego da internet para pesquisas } \\
\text { sobre temas específicos da química. }\end{array}$ \\
\hline & $\begin{array}{l}\text { [D7] Ciências } \\
\text { tecnologia e } \\
\text { sociedade (OBR) }\end{array}$ & $\begin{array}{lr}\text { Histórico da } & \text { ciência e da } \\
\text { tecnologia } & \text { como } \\
\text { construções } & \text { humanas, } \\
\text { inseridas em } & \text { contextos } \\
\text { sociais } & \text { específicos. } \\
\text { Diferença } & \text { entre } \\
\text { conhecimentos científicos e } \\
\text { tecnológicos. }\end{array}$ & $\begin{array}{l}\text { Histórico da ciência e da tecnologia como } \\
\text { construções humanas, inseridas em contextos sociais } \\
\text { específicos. Diferença entre conhecimentos } \\
\text { científicos e tecnológicos. O acúmulo do } \\
\text { conhecimento tecnológico e os processos de ruptura } \\
\text { dos modelos. O século XX e a relação Ciência- } \\
\begin{array}{l}\text { Tecnologia-Sociedade (CTS). Alfabetização } \\
\text { científica e tecnológica numa perspectiva de } \\
\text { educação científica escolar. }\end{array}\end{array}$ \\
\hline$[\mathrm{M}]$ & $\begin{array}{l}\text { [D8] Laboratório } \\
\text { de ensino do uso } \\
\text { de novas } \\
\text { tecnologias } \\
\text { (OBR) }\end{array}$ & $\begin{array}{l}\text { Fundamentação teórica e } \\
\text { metodológica do uso de } \\
\text { novas mídias na sala de aula } \\
\text { e o ensino de matemática. } \\
\text { Estudo e utilização de } \\
\text { Software para o ensino de } \\
\text { matemática. }\end{array}$ & $\begin{array}{l}\text { Fundamentação teórica e metodológica do uso de } \\
\text { novas mídias na sala de aula e o ensino de } \\
\text { matemática. Estudo e produção de materiais para o } \\
\text { uso de calculadora em sala de aula. Estudo do uso de } \\
\text { TV-DVD em sala de aula e produção de atividades } \\
\text { para o uso de vídeos da TV escola. Estudo e } \\
\text { produção de site como recurso didático. Estudo e } \\
\text { utilização de Software para o ensino de matemática. } \\
\text { Estudo do uso de filmes como recurso didático. }\end{array}$ \\
\hline
\end{tabular}


VII Congresso Brasileiro de Informática na Educação (CBIE 2018)

Anais do XXIV Workshop de Informática na Escola (WIE 2018)

\subsection{Comparação entre as Competências dos PPC e da Resolução}

Conforme a Resolução $n^{\circ} 01 / 2002$, os cursos de licenciatura devem possibilitar que os ingressos possam estudar, analisar e experimentar metodologias e estratégias que colaborem para a inserção das TIC no processo de ensino e aprendizagem. Além disso, o desenvolvimento de material de apoio para esse processo também deve ser motivado. Portanto, os PUDs de cada disciplina devem ser considerados para a escolha e para o uso adequado das TIC proporcionando novas formas de aprendizagem.

Neste sentido, a comparação considerou a presença de competências no PPC de cada curso (Quadro 1) juntamente com a identificação da(s) disciplina(s) responsável(eis) por desenvolver essa competência do currículo (Quadro 2). Para tanto, a competência da resolução foi dividida nas seguintes categorias relacionadas com as TIC: (i) uso das TIC [C1], relacionada com a capacitação da utilização das TIC pelos discentes, (ii) metodologia e estratégia [C2], possibilita o desenvolvimento de novas formas de ensino, considerando a transposição didática, as características dos alunos e dos objetivos do componente curricular, e (ii) confecção de materiais de apoio inovadores [C3], permite que os discentes desenvolvam a habilidade de propor novas ferramentas que facilitem o processo de ensino e aprendizagem. O Quadro 3 apresenta o resultado da comparação juntamente com o resultado utilizando a escala detalhada na Seção 4.

Quadro 3. Comparação entre as competências.

\begin{tabular}{|c|l|l|l|c|}
\hline CURSO & \multicolumn{1}{|c|}{ COMPETÊNCIA } & \multicolumn{1}{|c|}{ DISCIPLINA } & \multicolumn{1}{|c|}{ CATEGORIAS } & RESULTADO \\
\hline$[\mathrm{LP}]$ & {$[\mathrm{CLP} 1]$} & {$[\mathrm{D} 1][\mathrm{D} 2]$} & {$[\mathrm{C} 2]$} & Contempla \\
\hline$[\mathrm{H}]$ & {$[\mathrm{CH} 1]$} & Não apresenta & Não apresenta & Não contempla \\
\hline$[\mathrm{CB}]$ & {$[\mathrm{CCB} 1]$} & {$[\mathrm{D} 3][\mathrm{D} 4]$} & {$[\mathrm{C} 1][\mathrm{C} 2][\mathrm{C} 3]$} & Contempla parcialmente \\
\hline$[\mathrm{F}]$ & {$[\mathrm{CF} 1][\mathrm{CF} 2][\mathrm{CF} 3]$} & {$[\mathrm{D} 5]$} & {$[\mathrm{C} 1][\mathrm{C} 2][\mathrm{C} 3]$} & Contempla parcialmente \\
\hline$[\mathrm{Q}]$ & {$[\mathrm{CQ} 1][\mathrm{CQ} 2]$} & {$[\mathrm{D} 6][\mathrm{D} 7]$} & {$[\mathrm{C} 1][\mathrm{C} 2]$} & Contempla parcialmente \\
\hline$[\mathrm{M}]$ & {$[\mathrm{CM} 1][\mathrm{CM} 2][\mathrm{CM} 3][\mathrm{CM} 4][\mathrm{CM} 5]$} & {$[\mathrm{D} 8]$} & {$[\mathrm{C} 1][\mathrm{C} 2][\mathrm{C} 3]$} & Contempla parcialmente \\
\hline
\end{tabular}

Embora o curso de Letras-Português possua duas disciplinas para possibilitar a discussão da inclusão das TIC no processo de ensino e aprendizagem, elas não possibilitam que os discentes tenham uma formação sobre a utilização das TIC nem sobre a elaboração de materiais inovadores, ou seja, que utilizam as TIC para possibilitar novas formas de interação. Para o curso de História, não foi identificada nenhuma disciplina relacionada às TIC, por mais que o PCC do referido curso possua uma competência para desenvolver essa habilidade. Logo, esses cursos contemplam e não contemplam, respectivamente, a resolução $n^{o}$ 01/2002. Em relação aos demais cursos, eles contemplam parcialmente a inclusão das TIC. Mais especificamente, o curso de Ciências Biológicas apresenta duas disciplinas capazes de desenvolver a competência requerida na Resolução $n^{\circ} 1 / 2002$, porém elas são optativas. Logo, a necessidade dessa formação deve ser decidida pelos discentes, não uniformizando a formação docente nem seguindo a resolução. Para os cursos de Química e Matemática, as disciplinas ofertadas por esses cursos não são suficientes para satisfazer completamente a resolução, pois não possibilitam a formação dos discentes para a utilização das TIC. Por sua vez, o curso de Física possui competência e disciplina para este fim, porém não está descrito o ementário dessa disciplina no seu PPC.

Consequentemente, todos os cursos analisados não contemplam totalmente a resolução, porém corroboram com a necessidade de inclusão dos novos docentes na era digital discutida por Stahl (1997). Além disso, os resultados encontrados contradizem parcialmente o argumento de Paiva (2013), indicando que os cursos oferecidos pelas 
VII Congresso Brasileiro de Informática na Educação (CBIE 2018)

Anais do XXIV Workshop de Informática na Escola (WIE 2018)

universidades abordam o uso da tecnologia. Logo, pode-se observar que todos os cursos analisados possuem disciplinas para a abordagem desse tema. Entretanto, foram considerados apenas as competências e as disciplinas disponibilizadas nos PPC, ou seja, as atividades complementares, Práticas como Componentes Curriculares (PCC) e estágios supervisionados podem auxiliar na abordagem das TIC em sala de aula. Outro fator que pode ser considerado é o currículo oculto, porém ao não indicar no PPC a formação requerida, a abordagem fica a cargo do docente que ministrará a disciplina. Com isso, a formação docente passa a não ser uniforme.

\section{Considerações Finais}

Este artigo ao cumprir com o seu objetivo geral, conseguiu desvelar a proposta da formação docente dos cursos de Licenciatura oferecidos pela FAFIDAM em relação as TIC. Para tanto, foi realizado o estudo dos PPC dos cursos de licenciatura em LetrasPortuguês, História, Ciências Biológicas, Física, Química e Matemática, e, a partir desse estudo, foi possível obter um panorama geral, de como as TIC são implementadas no processo de formação dos licenciandos. Para alcançar este, e os demais objetivos da pesquisa, realizou-se um estudo bibliográfico e documental, que teve como principais instrumentos norteadores, a Resolução 01/2002 e os PPC e PUD dos cursos de Licenciatura em Letras-Português, História, Ciências Biológicas, Física, Química e Matemática oferecidos pela FAFIDAM. A constatação de que nem todos os cursos garantem a inserção das TIC na formação dos profissionais docentes evidencia que a utilização destes recursos ainda não está integrada no processo de formação de professores. Assim, essa realidade mostra que ainda existe uma grande divergência entre o modo como a tecnologia está presente na vida das pessoas, e como esses recursos estão sendo aproveitados como ferramenta metodológica que dê suporte ao processo de ensinar e aprender, dentro das instituições escolares. Além disso, fica explícita a necessidade de uma discussão e de novos estudos sobre os moldes do processo de formação dos profissionais docentes, pois, os sujeitos que serão responsáveis por conduzir os alunos em sua vida escolar, não devem estar alheios ao que a tecnologia oferece de recursos, que podem ser usados para favorecer o processo ensino e aprendizagem.

Como trabalhos futuros, destaca-se: (i) a análise dos demais cursos de licenciatura (Pedagogia, Geografia, Letras Inglês e Educação no Campo) oferecidos pela referira instituição, (ii) a análise da inclusão das TIC via atividades complementares, práticas como componente curricular e estágio supervisionado, e (iii) um estudo sobre o currículo oculto por meio de entrevistas com os professores que lecionam nas disciplinas analisadas.

\section{Referências}

BRASIL (2017) Senado Federal. Secretaria de Editoração e Publicações. Coordenação de Edições Técnicas. LDB - Lei de Diretrizes e Bases da Educação Nacional. Brasília, DF, 2017. Disponível em: $<$ http://www2.senado.leg.br/bdsf/bitstream/handle/id/529732/lei_de_ diretrizes_e_bases_1ed.pdf $>$. Acesso em: 03 jun. 2018.

CONSELHO PLENO (2002) Institui Diretrizes Curriculares Nacionais para a Formação de Professores da Educação Básica, em nível superior, curso de licenciatura, de graduação plena. Resolução n. 1, de 18 de fevereiro de 2002. Conselho Nacional de Educação. Disponível em: < http://portal.mec.gov.br/seesp/arquivos/pdf/res1_2.pdf>. Acesso em: 02 jun. 2018. 
VII Congresso Brasileiro de Informática na Educação (CBIE 2018)

Anais do XXIV Workshop de Informática na Escola (WIE 2018)

FREIRE, E. S. S. (2017) Análise da Proposta Formativa: Dimensões curriculares no curso técnico subsequente de informática. $15 \mathrm{f}$. Trabalho de Conclusão de Curso de Especialização em Formação Pedagógica para Docência na Educação Profissional e Tecnológica - Instituto Federal do Ceará, Fortaleza, 2017.

JOYE, C. R. (2014) Metodologia Científica. Fortaleza: SETEC/IFCE, 2014.

JUNQUEIRA, S. M. S.; MANRIQUE, A. L. (2015) Reformas curriculares em cursos de licenciatura de Matemática: intenções necessárias e insuficientes. In: Ciência \& Educação, Bauru, v. 21, n. 3, p. 623-635, 2015.

LEITE, Y. U. F. (2007) A formação de professores nos cursos de licenciatura: algumas diretrizes e práticas. In: XXIII Simpósio Brasileiro de Política e Administração da Educação. Porto Alegre, RS, 2007.

MOREIRA, A. F. B.; CANDAU, V. M. (2007) Indagações sobre Currículo: currículo, conhecimento e cultura. Brasília: Ministério da Educação, Secretaria de Educação Básica, 2007. 48p.

PAIVA, V. L. M. O. (2013) A formação do professor para uso da tecnologia. In: SILVA, K. A.; DANIEL, F. G.; KANEKO-MARQUES, S. M.; SALOMÃO, A. C. B. (Orgs) A formação de professores de línguas: Novos Olhares - Volume 2. Campinas, SP: Pontes Editores, 2013. pg. 209-230.

SAVIANNI, D. (2009) Formação de professores: aspectos históricos e teóricos do problema no contexto brasileiro. Revista Brasileira de Educação v. 14 n. 40 jan./abr. 2009.

SCHUHMACHER, V. R. N.; ALVES FILHO, J. P.; SCHUHMACHER, E. (2017) As barreiras da prática docente no uso das tecnologias de informação e comunicação. Ciência \& Educação v. 23 n. 3, 2017.

SILVA, T. T. (2010) Documentos de Identidade: uma introdução às teorias curriculares. 2 ed. Belo Horizonte: Autêntica, 2010. 156p.

SILVEIRA, E. A. (2015) Tecnologias e as mudanças de paradigma do ensino aprendizagem. 2015. 44 f. Trabalho de Conclusão de Curso de Especialização em Mídias na Educação - Centro Interdisciplinar de Novas Tecnologias na Educação, Universidade Federal do Rio Grande do Sul, 2015.

STAHL, M. M. (1997) Formação de professores para uso das novas tecnologias de comunicação e informação. CANDAU, V.M. (org.). Magistério: Construção Cotidiana. Petrópolis: Vozes, 1997.

UECE. Site institucional (2018) Disponível em: < http://www.uece.br/fafidam/index.php?option=com_content\&view $=$ article\&id $=90418 \&$ Itemid $=12 \&$ cssfile $=$ principal2.css $>$. Acessado em: 03 jun. 2018.

VIEIRA, F. L. S. (2018) A formação do professor na sociedade digital e a importância do professor mediador: novos modelos de ensinar e aprender. $2018.11 \mathrm{f}$. Trabalho de Conclusão de Curso de Especialização em Docência do Ensino Superior Centro de Ciências Empresariais e Sociais Aplicadas, Universidade Norte do Paraná, Limoeiro do Norte, 2018. 